\title{
Effect of Psycho-educational Nursing Program on Social Adjustment and Self- esteem among Substance Abusers
}

\author{
Shimaa Salah Elsayed ${ }^{1}$, Omayma Abu Bakr Othman², Maaly Ibrahim El Malky ${ }^{3}$ and \\ Mawaheb Mahmoud Zaki ${ }^{4}$
}

(1)Assistant lecturer of psychiatric and mental health nursing Benha University (2) Professor of psychiatric \& mental health nursing Ain Shams University (3) Professor of psychiatric \& mental health nursing El-Menoufia University and (4) Assistant professor of psychiatric \& mental health nursing Benha University

\begin{abstract}
Substance abuse is one of the most important social deviations, which is foundation of many social damages and problems at the community level. Every part of the substance abuser's life as social life, family life, work productivity, physical health and personal relationships is affected. Aim: The aim of the present study was to determine the effect of psycho-educational nursing program on social adjustment and self-esteem among substance abusers. Design: A quasiexperimental design (pre and posttest) was used to achieve the aim of the study. Setting: This study was conducted at the outpatient clinics for addiction at the Psychiatric Mental Health Hospital in Benha City, Qalubia Governorate, which is affiliated to General Secretariat of Mental Health in Egypt. Subject: A convenience sample of 40 substance abusers was included from the above setting for conduction of this study. Tools: Three tools were used for data collection. Tool 1- structured interview questionnaire was used to collect data about socio demographic and clinical characteristics of the studied sample. Tool 2- Social Adjustment scale (SAS) to assess social adjustment of different life domains among the studied sample. Tool 3- Self-esteem scale (SES) was used to assess self-esteem among the studied sample. Results: There was a highly statistically significant improvement in total score of social adjustment and total score of self-esteem between pre and post implementation of the program. Conclusion: The study demonstrated that psychoeducational nursing program had a positive effect on enhancement of social adjustment and selfesteem among substance abusers. Recommendations: A psycho educational program should be given for all substance abusers based on a treatment protocol during their hospitalization to enhance their self-esteem and social adjustment.
\end{abstract}

Key words: Substance abuse, social adjustment, self-esteem, psycho-educational nursing program.

\section{Introduction}

Substance abuse has a major impact on individuals, families, and communities as its effects are cumulative, contributing to costly social, physical and mental health problems. Several factors can enhance the risk for initiating or continuing substance abuse including socio-demographic status, quality of parenting, peer group influence and biological/ inhalant predisposition toward substance abuse (Salam et al., 2016).

Also, Substance abuse represents a condition whereby drug-taking and drugseeking come to dominate behavior to such a degree that drug use appears to control over behavior that was once influenced by normal environmental reinforces. For many 
individuals, the pattern of abusive drug use continuous despite serious adverse effects and repeated efforts to abstain. Both individuals, families are destroyed. Every part of the substance abuser's life as social life, family life, work productivity, physical health and personal relationships is affected. Substance abuse in work environment increases accidents, theft, absenteeism and workers' compensation claims while decreasing in the quality of work performed overall (Yazdani \& Abardeh, 2018).

Likewise, Substance abuse is a pattern of recurrent use that leads to damaging consequences. Which may involve failure to meet one's major role responsibilities, putting oneself in situations where substance use is physically dangerous, encountering repeated problems with the law arising from substance use (e.g., multiple arrests for substance related behavior), or having recurring social or interpersonal problems because of substance use (e.g., repeatedly getting into fights when drinking). When people repeatedly miss school or work because they are drunk or sleeping it off their behavior may fit the definition of substance abuse (American Psychiatric Association, 2016).

Substance abuse influences people's selfesteem in their personal lives. Self-esteem refers to individual's perception or subjective appraisals of one's own self-worth, one's feelings of self-respect, self-confidence and the extent to which the individual holds positive or negative views about self. Because substance abuse leaves many negative impacts on the self-esteem via the cognitive and psychological alterations it causes. Low self-esteem leads to feeling of failure, dissatisfaction of one's role in the society, dissatisfaction of quality of life, impaired interpersonal skills, social interactions and social adjustment. So, improved of positive self-concept or healthy self-esteem is extremely important for good adjustment for individual in society (Heidari \& Ghodusi, 2016).

Social adjustment of a drug addict is a process of social bonds renewal between the personality and the out world. Substance abusers have a lack of adjustment skills and maladaptive adjustment style for navigating through their day- to-day life. Difficulties in adjustment can be the result of personenvironment interactions, such as biological predispositions and precipitating stressful environmental demands, which can include long term stress or the buildup of daily hassles (Benyamini, 2015).

Social adjustment is a continuous process in which social learning experiences of person is causing his emotional needs and also provides the possibility of acquiring ability and skills through which he can be focus to satisfy his needs. Peoples with high selfesteem believe they have social worth and consequently engage in behaviors that build social support. In contrast, people with low self-esteem may avoid social relationships to avoid rejection and thereby fail to build or maintain social adaptation systems. A selfesteem consequence model, however, suggests that positive social adaptation produces higher self-esteem, or greater sense of social worth. That is, self-esteem may be just reflection of being more socially connected or valued (Marshall et al., 2014).

Psycho-educational nursing program works to reintegrate substance abusers after recovery with the community to become productive and positively influencing individuals. It also helps to reform his thinking and behavioral changes to achieve a 
healthy life, as well as to teach the patient how to cope with difficult situations that may lead him to think about substance abuse. The program help the individual to relapse prevention of substance, improve self-esteem, social adjustment and achieve productive functioning in the families, at work and in society (Samhsa, 2017).

Nurses play a vital role in helping patients undergoing drug rehabilitation. They teach patients about the dangers of drug abuse, including the physical and psychological effects; the damage to relationships and family life; and the impact on meeting basic needs such as holding down a job. They monitor their progress, help them adjust to life without substances and teach them how to maintain their sobriety after leaving hospital. Nursing role in communication and social skills training leads to elevation of the level of individual capabilities and one's sense of self-esteem on one hand, and development of communications network and attraction of more social support due to providing the possibility to use the learned capabilities in society and interpersonal relationships on the other hand (Jahedi \& Reyshahri, 2015).

\section{Significance of the study}

Substance abuse is one of the most important social deviations, which is foundation of many social damages and problems at the community level. In Egypt according to (The fund for fighting and treating addiction and administration), in 2019, substance abuse estimated up to $(10.4 \%)$ in the age group of 15 to 60 years and there are some categories spread by substance such as the category of drivers and represent $(24 \%)$. Tramadol is the most common substance in Egypt among users, where represent $(36.2 \%),(26 \%)$ hashish and $(18.3 \%)$ of abusers taking heroin. In fact substance abuse leads to deterioration in personality and physical energy of the individual and a withdrawal from the active domains of life. Researches has shown that physical and psychological consequences of substance abuse lead to the reduction in selfesteem and social adjustment ( Asghari et al., 2016).

\section{Methodology \\ Aim of the Study}

This study aimed to determine the effect of psycho-educational nursing program on social adjustment and self-esteem among substance abusers.

\section{This aim will be achieved through:}

- Assessing social adjustment and self-esteem among substance abusers.

- Designing psycho-educational nursing program for social adjustment and selfesteem.

- Implementing psycho-educational nursing program on substance abusers.

- Evaluating the effect of psycho-educational nursing program on social adjustment and self-esteem among substance abusers.

- Subject and methods of this study were portrayed under four main topics as follow:

\section{I- Technical design:}

\section{Research Design:}

A quasi experimental design was used to achieve the aim of the study.

\section{Research Setting:}

This study was conducted at the outpatient clinics for addiction at the Psychiatric Mental Health Hospital in Benha 
City, Qalubia Governorate, which is affiliated to General Secretariat of Mental Health in Egypt.

Out-patients clinics for addiction are treating and caring the substance abuse patients essentially. Out-patients clinics for addiction works from $9 \mathrm{am}$ to $1 \mathrm{pm}$ per, two days / week (Monday and Tuesday every week). Also, it provides Hotline Services for substance abusers 2 days/ week (Sunday and Thursday) through which the psychiatrist gives group therapy and programs for substance abusers. Psychiatrist and two psychiatric nurses worked in Out-patients clinics for addiction during the day. It consisted of one room for examination that contained of two desk and chairs around the desk.

\section{Research Subject:}

\section{Sample size:}

The estimated sample size was 40 patients, at confidence level $95 \%$ and precision rate 0.05 .

\section{Sample technique:}

Sample technique:

A convenience sample of 40 substance abusers from Benha Psychiatric and Mental Health Hospital were selected from the outpatient clinics of addiction. This sample should meet the following inclusion criteria:

1- Able to communicate relevantly and willing and agreeing to participate in the study.

2- Free from any organic brain disorders and other psychotic disorders.

3- After the withdrawal phase of treatment.

\section{Tools of Data Collection:}

The data was collected using the following tools:

1-Tool (1):- A structured Interview Questionnaire which developed by the researcher \& consists of two parts :

Part I:- Socio-demographic data: To elicit data about the patients characteristics such as age, marital status, level of education, occupational status, monthly income, with whom you live and If you have a problem, who should you turn to.

Part II: - Clinical data: which includes: number of years of substance abuse, types and number of substance abuse that patients take, number of times substance abused, is this the first attempt to stop substance abused?, how many times have you tried treatment form substance abuse?, what are the motivations for substance abused and causes of relapse from substance abused.

\section{2-Tool (2): Self- esteem Scale(SES):}

Hudson, (1994), originally developed self-esteem Scale to measure problems of personal self-evaluation. It was translated into Arabic language El-Desouky, (2000). This scale is composed of 25 items, which modified by the researcher after revision by jury of 5 experts in psychiatric field. It was adopted by the researcher to be 20 items and rated on a 3-point likert scale that range as following:- $(0)=$ never, $(1)=$ sometimes and (2) =all the time. Some sentences number $(1,2,3,4,5,6,7,8$, and question 9) are reverse scored. High score is indicate of low selfesteem, moderate is indicate moderate selfesteem and lower score is indicate high selfesteem. 
Scoring system of self-esteem scale:

$\square<50 \% \quad$ indicated high self-esteem

$\square 50-70 \%$ indicated moderate self-esteem

$\square>70 \% \quad$ indicated low self-esteem

\section{II- Operational design:}

\section{- Preparatory Phase:-}

This included reviewing of relevant literature of different studies related to the topic of research using textbooks, articles, and magazines to get clear pictures of all the aspects related to the research topic to design the program.

\section{- Content Validity:}

A group of five experts did validity of tools. Two of them were specialized in the psychiatric medicine and the other three were specialized in the psychiatric nursing field to check the relevancy, clarity, comprehensiveness, and applicability of the questions. According to their opinions,

\section{3-Tool (3): Social Adjustment Scale (SAS):}

Social Adjustment Scale was developed by Abdel Wahab, (1990). This was designed to assess the substance abusers social adjustment of different life domains. It was translated into Arabic by Abdel Salam, (2011), this scale composed of 40 item in the form rating scale ranging from (1-3). The items are divided into five subscale, 8 items to measure the performance of the patient during treatment, 10 items to measure patient's

\section{- Pilot Study:}

Before starting data, collection a pilot study was conducted to assess the clarity and applicability of the study tools, and identify the time needed to fill each tool. It was carried out on $10 \%$ of the subjects, who were excluded from the main study sample. According to the result of the pilot study necessary modification was done as follow: modifications were done as, Modification of some words of Arabic form of Social Adjustment Scale (SAS) to give the right meaning of the phrase, Adoption of Selfesteem Scale (SES) to be 20 items rating scale. This modification was done with the objective of its accuracy and consistency, and to avoid repetition of some points of scale and modification of some words in the Arabic form of the tool to give the right meaning of the phrase and the final form was developed.

\section{- Reliability of the tool:}

Test-retest reliability was applied for tool (Social Adjustment Scale and Selfesteem Scale). The tools proved to be strongly reliable (r. $=0.823$ and 0.799$)$ respectively.

This included reviewing of relevant literature of different studies related to the topic of research using textbooks, articles, and magazines to get clear pictures of all the aspects

activities of daily life, 12 items to measure patients social role performance, 5 items to measure patients personal hygiene, and 5 items to measure patients interesting in external events.

\section{The scale scoring system:}

Less than (61) low social adjustment. From (61) to (99) moderate adjustment.

From (100) to (120) high adjustment.

Adoption for Self-esteem Scale to be 20 items rating scale to avoid repetition of some points of scale and modification of some words in the Arabic form of (Social Adjustment Scale and Self- esteem Scale) to give the right meaning of the phrase. 


\section{-Field work:}

\section{Designing phase:-}

This phase aimed at designing for the psychoeducational nursing program through setting educational objectives, preparing the psychoeducational nursing program and designing the methodology and media.

Development of psycho-educational nursing program: -

The psycho-educational nursing program was developed by the researcher after a thorough review of the related literatures and after making of the pilot study. The psychoeducational nursing program aimed to improve social adjustment and self-esteem among substance abusers. This program has a set of general objectives, and specific objectives for each session. The number of program's sessions was 15 sessions. Based on the results obtained from the assessment tools and review of literature, the program content was developed by the researcher in the form of a booklet, which was revised and approved by the supervisors, after that the final booklet is distributed for substance abusers in the first session.

\section{General Objectives of the group activity therapy program:-}

At the end of the Psycho-educational Nursing Program implementation, the following must be achieved for substance abusers:

- Improving self-esteem and social adjustment among substance abusers.

- Helping substance abusers to feel able to live and to accept others without resorting to drugs.
- Helping substance abusers to create a new life through the skills they have learned and interact with others through new life style.

\section{Specific Objectives of psycho-educational nursing program:}

At the end of the psycho-educational nursing program implementation, the participant will be able to:

1-Recognize meaning of substance abuse and its causes.

2- Discuss effects of substance abuse on individual and society.

3- List phases of treatment from substance abuse.

Discuss methods of relapse prevention among substance abusers.

5- Recognize the meaning of self -esteem and its importance in the treatment of addiction.

6-Recognize characteristic of people with low self-esteem and its effect on their lives.

7-Recognize the meaning and signs of weakness of assertiveness.

8-Identify characteristic of people who use assertiveness.

9-Discuss situations faced substance abusers and how to deal with it.

10-Training on expression of feelings and emotions experienced by the participants in their dealings with their lives.

11-Practice steps to promotion of self-esteem.

12-Practice methods of improve verbal \& non-verbal communication.

13- Practice methods of effective listening.

14- Training on assertiveness skills.

15- Training on overcome negative thoughts.

16-Training on relaxation technique. 


\section{Implementation Phase:-}

This phase was beginning by data collection then implementation of psychoeducational nursing program for substance abusers (study group) who meet previously mentioned criteria.

\section{1- Data collection (Pre-test):}

Data collection of this study was carried out at outpatient clinic for addiction at the Psychiatric Mental Health Hospital at Benha City, Kaluobia Governorate. The data collection was done on study group (pre test) in first session (acquaintance session) after identify the purpose of the program, describe schedule of the program (number of sessions, time and duration of each session) and outlines the content and steps of the program.

\section{2- Implementation of the Program:}

- This step focused on the implementation of Psycho-educational Nursing Program for the study group (40 substance abusers). This group was divided into 8 subgroups; each subgroup composed of 5 patients.

- The program consisted of 15 sessions, 3,5 hours sessions theoretical and 9 hours sessions practical. Each subgroup received 15 sessions of psycho-educational nursing program.

- Sessions was implemented two day per week for 30 minutes to 60 minutes for each session. Days / week, Usually at Monday and Tuesday every week.

- The sessions of psycho-educational nursing program were carried out in 13 months during the period of (1/November-2019 to 1/December2020).
- Researcher work with (8 subgroup, 2days/week). Each subgroup composed of 5 patients.

- Each subgroup composed of 5 patients received one session/day /week which lasted for about 30-60 minute and 10 minute for break.

- The program sessions were conducted in the outpatient clinic for addiction, entertainment hall and room for group therapy (includes chairs arranged in 2 raw and table for the equipment).

- To ensure that the patients understand the program contents, each session was started with a summary about what was given through the previous session, and the objectives of the new session were mentioned taking into consideration using simple language to suit all patients.

- During the session, the researcher used demonstration, and modeling by the researcher and one patient to practice skills in psycho-educational nursing program. After that, the researcher used re- demonstration of the skill by each patient to master the skill. After finishing, the researcher thanked the patients for participation and encouraged the patients for asking about any unclear points.

- Moreover, the researcher made a summary at the end of the session and told the patients about the time of the next session.

\section{3-Strategies of program implementation:-}

- Methods of teaching- Open discussion, group discussion, brain storming, 
demonstration, real situation, positive reinforcement, modeling, group cooperation, role play.

- Media: - brochure and video tape.

- Methods of evaluation:- Feedback through oral questions, re-demonstration, positive participation, direct observation, role play.

\section{4- Evaluation Phase (post-test).}

-This phase aimed to estimate the effect of psycho-educational nursing program on improvement of self-esteem and social adjustment on substance abusers. After the conduction of the psycho-educational nursing program sessions for the study group a posttest was done for study group using the pervious assessment tool for data collection (tool two and three for data collection ) to compare the effect of the program pre post intervention .

\section{III- Administrative design:}

\section{- Approval:}

A written letter was issued from the Dean of Faculty of Nursing, Benha University to obtain the approval for data collection from the director of Psychiatric Mental hospital at Benha City Kaluobia Governorate. An official approval was obtained from the director of the Psychiatric Mental Health Hospital at Benha City, Kaluobia Governorate. Moreover an official approval was obtained from the Human Rights Protection Committee and Research Committee of General Secretariat of Mental Health in Egypt after revision of the study protocol, tools, and the booklet. The purpose and the nature of the study were explained to the hospital's staff, and then it was possible to carry out the study with minimum resistance.

\section{- Ethical Consideration:}

Before conducting the study the participants were assured about confidentiality and anonymity of their obtained information throughout the study. They were informed about their right to refuse to participate in the study and the right to withdraw from the study at any time. Acceptance of participants who agreed to participate in the study was taken from the participants through a written consent filled by assistance of the patients' rights committee in the hospital.

\section{IV-Statistical Design:}

The collected data were organized, computerized, tabulated and analyzed by using the Statistical Package for Social Science (SPSS) version 20. Data analysis was accomplished by the use of number, percentage distribution, mean, and standard deviation. Paired t-test was used to compare means within group, and t-test was used to compare two independent means. A significant level value was considered when p- value $=<0.05$.

\section{Difficulties of the Study:}

-Substance abusers were not all motivated and more effort was paid to make them actively participate.

- The program implemented in outpatient clinic only because the inpatient not available to receive patients.

- Lack of privacy during program implementation. There was no special place for conducting the program; hence, the researcher conducted the program in the outpatients' clinic and sometimes in room of group therapy or entertainment hall. Because of this, other people, which lead to increased 
distractibility of the studied participants, exposed the researcher to interruptions and sometimes the researcher was obliged to repeat or even start again.

\section{Results:}

Table (1) reveals that, more than half (55\% )of the studied patients have high selfesteem level post implementation of psychoeducational nursing program compared to only $(10 \%)$ who have high self-esteem before implementation of the program with a highly statistical significant difference at $(\mathrm{P}=<$ 0.000) .

Table (2) demonstrates that, there is a marked improvement in the mean score of all items of social adjustment as well as total social adjustment mean score post intervention than pre intervention with statistical significance difference between pre and post implementation of psychoeducational nursing program at $(\mathrm{P}$ value $=<$ 0.000).

Table (3) shows that, there are highly statistically significant difference between level of self-esteem of the studied patients and their educational level, occupation and with whom they live post intervention of the psychoeducational nursing intervention program at $(\mathrm{P}=$ $<0.01)$. The higher level self-esteem from those who have high self-esteem are among those who are living with their family(100\%), those who have intermediate education ( $45.5 \%)$ and those who are working( $100 \%)$.In addition, there are statistically significant difference between level of self-esteem and the patients age as well as monthly income at $(\mathrm{P}=<0.05)$. Where the higher level of self-esteem $(50 \%)$ for those who have high self-esteem are among age group between age of $35-<45$ years also the higher level of self-esteem $(54.5 \%)$ for those who have high self-esteem are among those who have poor income.

Table (4) shows that, there is a highly statistically significant difference between level of self-esteem of the studied patients at post intervention of psycho-educational nursing program and their attempt to stop substance abused at $(\mathrm{P}=<0.01)$. Where the higher level of self-esteem are among those who have first attempt to stop substance abuse. In addition, there is statistically significant difference between self-esteem and both of their duration of substance abuse and number of times they abused substance at $(\mathrm{P}=<0.05)$. The higher level of self-esteem is among those who abuse substance from $5<10$ years duration and who abuse substance daily (81. 8\%).

Table (5) shows that, there are highly statistically significant difference between level of social adjustment of the studied patients and their educational level, occupation and monthly income post intervention of psycho-educational nursing program at $(\mathrm{P}=<0.01)$. The higher level of social adjustment are among patients who are working $(100 \%)$, patients who have poor income $(54.2 \%)$ and patients who have intermediate education(45.8\%) respectively. Also, there are statistically significant difference between level of social adjustment and the patients age group, marital status and with whom they live at $(\mathrm{P}=<0.05)$. The higher level of social adjustment $(50 \%)$ are at age group between $25-<35$, single marital status $(62.5 \%)$ and those who live with their family member $(95.8 \%)$.

Figure (1) reveals that, more than half of the studied patients $(60 \%)$ have high level of social adjustment post nursing intervention program compared to only (10\%) who have high level of social adjustment before nursing 
intervention program with statistical significance difference between pre and post implementation of psycho-educational nursing program at $(\mathrm{P}$ value $=<0.000)$.

Table (6) shows that, there is a highly statistically significant difference between the level of social adjustment of the studied patients at post intervention of psychoeducational nursing program and their attempt to stop substance abuse at $(\mathrm{P}=<$ 0.01). The higher social adjustment is among those who have the first attempt to stop the substance abuse. In addition, there is statistically significant difference between social adjustment and both of duration of substance abuse and frequency of substance abuse at $(\mathrm{P}=<0.05)$. The higher social adjustment are $\mathrm{r}$ among those who abuse the substance daily $(79.2 \%)$ with duration from 5 $<10$ years $(62.5 \%)$. 
Table (1): Level of self-esteem of the studied patients at pre and post intervention of psychoeducational nursing program $(n=40)$.

\begin{tabular}{|c|c|c|c|c|c|c|}
\hline \multirow{3}{*}{ Total self-esteem } & \multirow{2}{*}{\multicolumn{2}{|c|}{$\begin{array}{c}\text { Pre-psycho- } \\
\text { educational } \\
\text { nursing } \\
\text { program }\end{array}$}} & \multirow{2}{*}{\multicolumn{2}{|c|}{$\begin{array}{c}\text { Post- } \\
\text { psycho- } \\
\text { educational } \\
\text { nursing } \\
\text { program }\end{array}$}} & \multicolumn{2}{|c|}{ T. test } \\
\hline & & & & & \multirow[t]{2}{*}{$\mathbf{X 2}$} & \multirow[t]{2}{*}{ p-value } \\
\hline & $\mathbf{N}$ & $\%$ & $\mathbf{N}$ & $\%$ & & \\
\hline High self-esteem & 4 & 10 & 22 & 55 & \multirow{3}{*}{25.36} & \multirow{3}{*}{$.000 * *$} \\
\hline Moderate self-esteem & 9 & 22.5 & 10 & 25 & & \\
\hline Low self-esteem & 27 & 67.5 & 8 & 20 & & \\
\hline
\end{tabular}

Table (2): The total mean score of social adjustment of the studied patients at pre and post intervention of psycho-educational nursing program $(n=40)$.

\begin{tabular}{|c|c|c|c|c|}
\hline \multirow[t]{3}{*}{ Items of social adjustment } & \multirow{2}{*}{$\begin{array}{c}\text { Pre-psycho- } \\
\text { educational } \\
\text { nursing } \\
\text { program }\end{array}$} & \multirow{2}{*}{$\begin{array}{c}\text { Post- psycho- } \\
\text { educational } \\
\text { nursing } \\
\text { program }\end{array}$} & \multicolumn{2}{|c|}{ T. test } \\
\hline & & & $\mathbf{X} 2$ & p-value \\
\hline & Mean SD & Mean SD & & \\
\hline Performance at work & $10.29 \pm 4.66$ & $19.67 \pm 5.93$ & 32.56 & $.000 * *$ \\
\hline Activities of daily living & $9.17 \pm 6.13$ & $23.52 \pm 5.78$ & 30.71 & $.000 * *$ \\
\hline Social function and Social performance & $15.06 \pm 5.72$ & $28.49 \pm 7.04$ & 29.45 & $.000 * *$ \\
\hline Personal hygiene & $7.35 \pm 2.83$ & $12.61 \pm 2.13$ & 26.31 & $.000 * *$ \\
\hline Enjoy or interest with external events & $6.22 \pm 1.47$ & $12.50 \pm 2.75$ & 26.31 & $.000 * *$ \\
\hline Total social adjustment & $49.67 \pm 11.89$ & $97.88 \pm 17.90$ & 21.77 & $.000 * *$ \\
\hline
\end{tabular}


Table (3): Relationship between socio-demographic characteristics of the studied patients and their total self-esteem at post intervention of psycho- educational nursing program $(n=40)$.

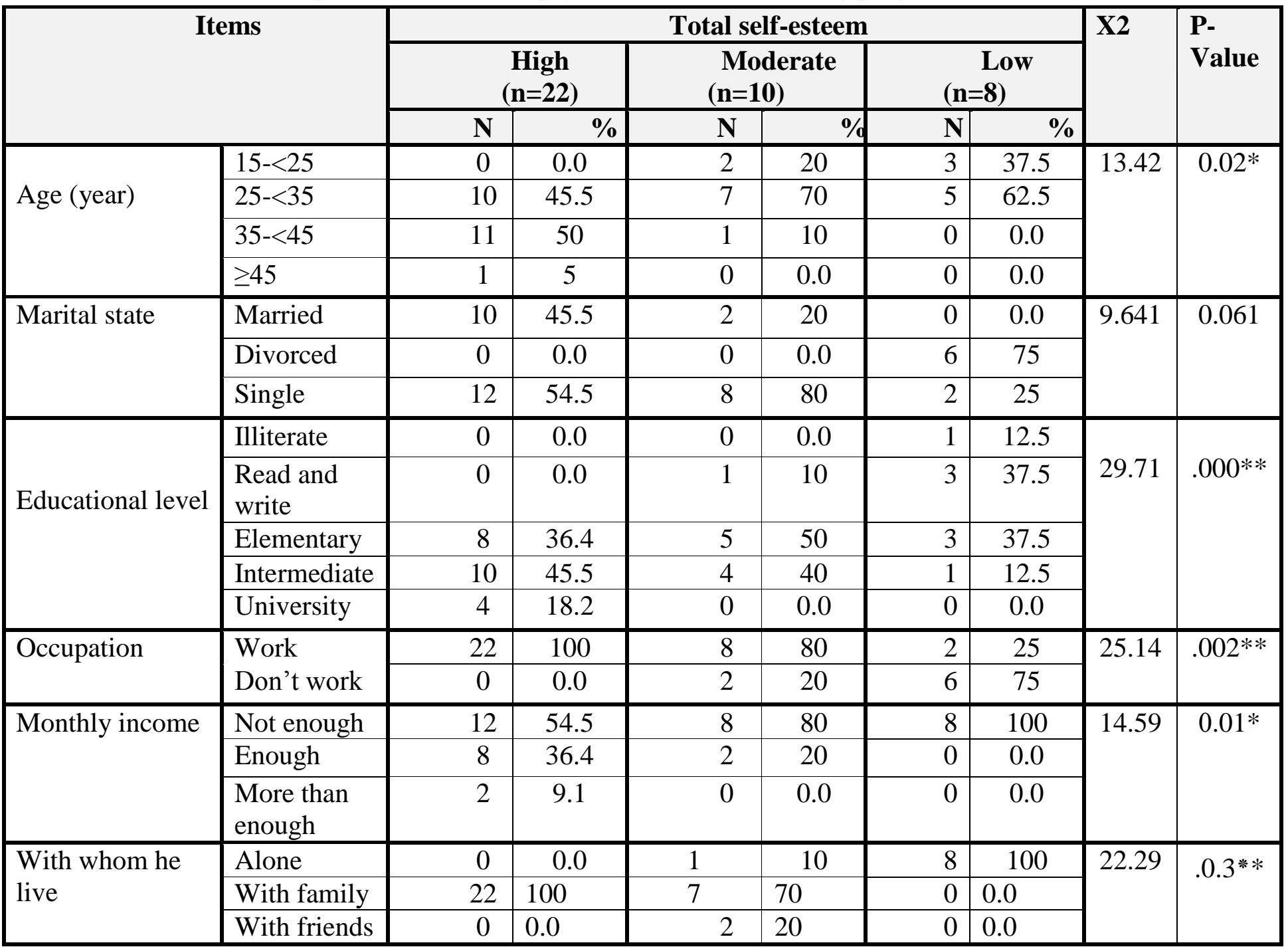


Table (4): Relationship between history of substance abuse of the studied patients and their level of self-esteem at post intervention of psycho-educational nursing program $(n=40)$.

\begin{tabular}{|c|c|c|c|c|c|c|c|c|c|}
\hline \multirow[t]{3}{*}{ Items } & & \multicolumn{6}{|c|}{ Total self-esteem } & \multirow[t]{3}{*}{$\mathbf{X 2}$} & \multirow{3}{*}{$\begin{array}{l}\text { P- } \\
\text { Value }\end{array}$} \\
\hline & & \multicolumn{2}{|c|}{$\begin{array}{c}\text { High } \\
(n=22)\end{array}$} & \multicolumn{2}{|c|}{$\begin{array}{l}\text { Moderate } \\
(\mathrm{n}=10)\end{array}$} & \multicolumn{2}{|c|}{$\begin{array}{c}\text { Low } \\
(n=8)\end{array}$} & & \\
\hline & & $\mathbf{N}$ & $\%$ & $\mathbf{N}$ & $\%$ & $\mathbf{N}$ & $\%$ & & \\
\hline \multirow{4}{*}{ Age (year) } & $15-<25$ & 0 & 0.0 & 2 & 20 & 3 & 37.5 & \multirow[t]{4}{*}{13.42} & \multirow[t]{4}{*}{$0.02 *$} \\
\hline & $25-<35$ & 10 & 45.5 & 7 & 70 & 5 & 62.5 & & \\
\hline & $35-<45$ & 11 & 50 & 1 & 10 & 0 & 0.0 & & \\
\hline & $\geq 45$ & 1 & 5 & 0 & 0.0 & 0 & 0.0 & & \\
\hline \multirow[t]{3}{*}{ Marital state } & Married & 10 & 45.5 & 2 & 20 & 0 & 0.0 & \multirow[t]{3}{*}{9.641} & \multirow[t]{3}{*}{0.061} \\
\hline & Divorced & 0 & 0.0 & 0 & 0.0 & 6 & 75 & & \\
\hline & Single & 12 & 54.5 & 8 & 80 & 2 & 25 & & \\
\hline \multirow{5}{*}{ Educational level } & Illiterate & 0 & 0.0 & 0 & 0.0 & 1 & 12.5 & \multirow{5}{*}{29.71} & \multirow{5}{*}{$000 * *$} \\
\hline & $\begin{array}{l}\text { Read and } \\
\text { write }\end{array}$ & 0 & 0.0 & 1 & 10 & 3 & 37.5 & & \\
\hline & Elementary & 8 & 36.4 & 5 & 50 & 3 & 37.5 & & \\
\hline & Intermediate & 10 & 45.5 & 4 & 40 & 1 & 12.5 & & \\
\hline & University & 4 & 18.2 & 0 & 0.0 & 0 & 0.0 & & \\
\hline \multirow[t]{2}{*}{ Occupation } & Work & 22 & 100 & 8 & 80 & 2 & 25 & \multirow[t]{2}{*}{25.14} & \multirow[t]{2}{*}{$.002 * *$} \\
\hline & Don't work & 0 & 0.0 & 2 & 20 & 6 & 75 & & \\
\hline \multirow[t]{3}{*}{ Monthly income } & Not enough & 12 & 54.5 & 8 & 80 & 8 & 100 & \multirow[t]{3}{*}{14.59} & \multirow[t]{3}{*}{$0.01 *$} \\
\hline & Enough & 8 & 36.4 & 2 & 20 & 0 & 0.0 & & \\
\hline & $\begin{array}{l}\text { More than } \\
\text { enough }\end{array}$ & 2 & 9.1 & 0 & 0.0 & 0 & 0.0 & & \\
\hline \multirow{3}{*}{$\begin{array}{l}\text { With whom he } \\
\text { live }\end{array}$} & Alone & 0 & 0.0 & 1 & 10 & 8 & 100 & \multirow[t]{3}{*}{22.29} & \multirow[t]{3}{*}{$.003 * *$} \\
\hline & $\begin{array}{l}\text { With } \\
\text { family }\end{array}$ & 22 & 100 & 7 & 70 & 0 & 0.0 & & \\
\hline & $\begin{array}{l}\text { With } \\
\text { friends }\end{array}$ & 0 & 0.0 & 2 & 20 & 0 & 0.0 & & \\
\hline
\end{tabular}


Table (5): Relationship between socio-demographic characteristics of the studied patients and their level of social adjustment at post intervention of psycho-educational nursing program $(n=40)$.

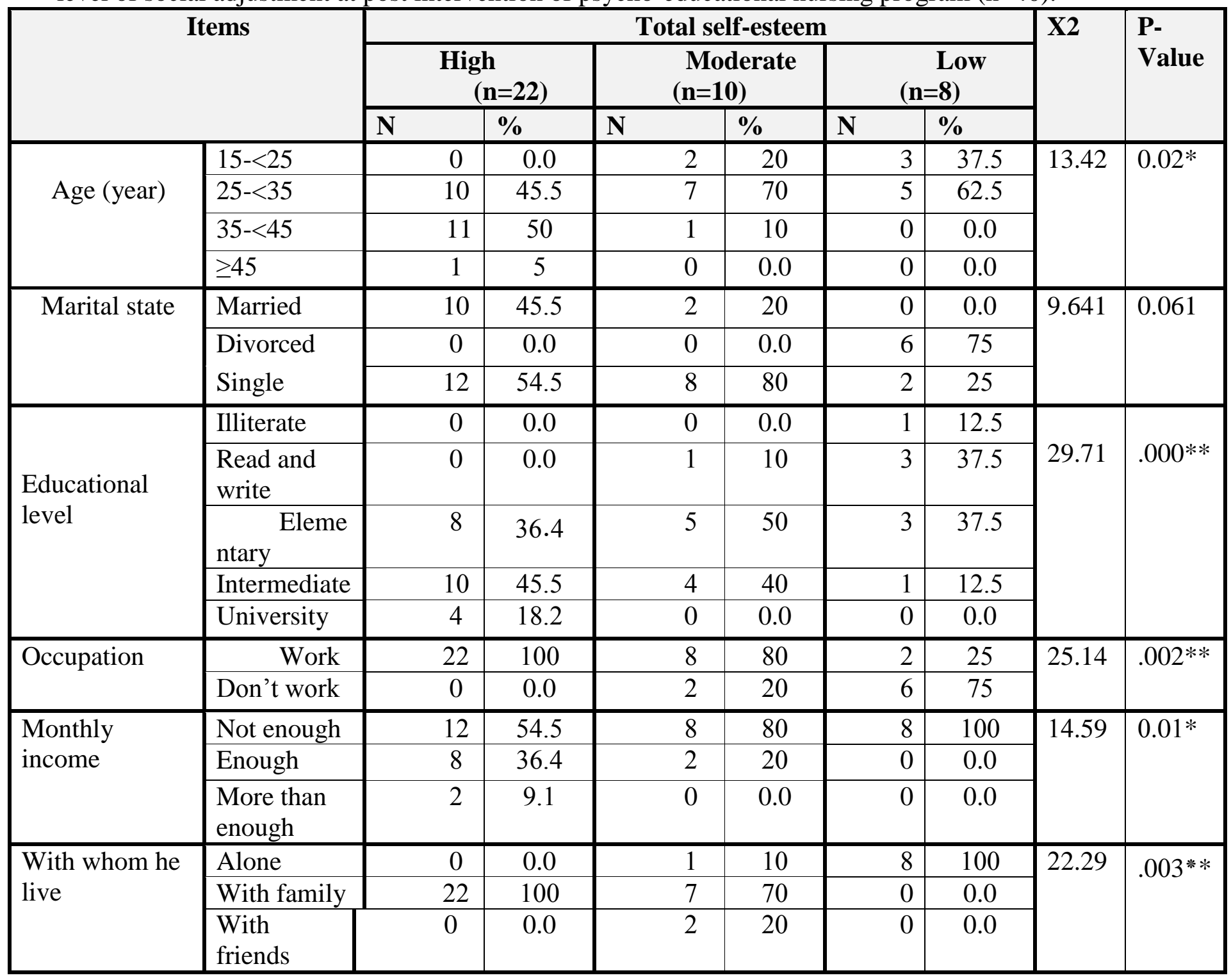


Table (6): Relationship between history of substance abuse of the studied patients and their level of social adjustment at post intervention of psycho-educational nursing program $(n=40)$.

\begin{tabular}{|c|c|c|c|c|c|c|c|c|c|}
\hline \multirow[t]{3}{*}{ Items } & & \multicolumn{6}{|c|}{ Total self-esteem } & \multirow[t]{3}{*}{$\mathbf{X} 2$} & \multirow{3}{*}{$\begin{array}{l}\text { P- } \\
\text { Value }\end{array}$} \\
\hline & & \multicolumn{2}{|c|}{$\begin{array}{c}\text { High } \\
(\mathrm{n}=22)\end{array}$} & \multicolumn{2}{|c|}{$\begin{array}{l}\text { Moderate } \\
(n=10)\end{array}$} & \multicolumn{2}{|c|}{$\begin{array}{c}\text { Low } \\
(n=8)\end{array}$} & & \\
\hline & & $\bar{N}$ & $\%$ & $\mathbf{N}$ & $\%$ & $\overline{\mathbf{N}}$ & $\%$ & & \\
\hline \multirow{4}{*}{ Age (year) } & $15-<25$ & 0 & 0.0 & 2 & 20 & 3 & 37.5 & \multirow[t]{4}{*}{13.42} & \multirow[t]{4}{*}{$0.02 *$} \\
\hline & $25-<35$ & 10 & 45.5 & 7 & 70 & 5 & 62.5 & & \\
\hline & $35-<45$ & 11 & 50 & 1 & 10 & 0 & 0.0 & & \\
\hline & $\geq 45$ & 1 & 5 & 0 & 0.0 & 0 & 0.0 & & \\
\hline \multirow[t]{3}{*}{ Marital state } & Married & 10 & 45.5 & 2 & 20 & $\overline{0}$ & 0.0 & \multirow[t]{3}{*}{9.641} & \multirow[t]{3}{*}{0.061} \\
\hline & Divorced & 0 & 0.0 & 0 & 0.0 & 6 & 75 & & \\
\hline & Single & 12 & 54.5 & 8 & 80 & 2 & 25 & & \\
\hline \multirow{5}{*}{ Educational level } & Illiterate & 0 & 0.0 & 0 & 0.0 & 1 & 12.5 & \multirow{5}{*}{29.71} & \multirow{5}{*}{$.000^{* *}$} \\
\hline & $\begin{array}{l}\text { Read and } \\
\text { write }\end{array}$ & 0 & 0.0 & 1 & 10 & 3 & 37.5 & & \\
\hline & Elementary & 8 & 36.4 & 5 & 50 & 3 & 37.5 & & \\
\hline & Intermediate & 10 & 45.5 & 4 & 40 & 1 & 12.5 & & \\
\hline & University & 4 & 18.2 & 0 & 0.0 & 0 & 0.0 & & \\
\hline \multirow[t]{2}{*}{ Occupation } & Work & 22 & 100 & 8 & 80 & 2 & 52 & \multirow[t]{2}{*}{25.14} & \multirow[t]{2}{*}{$.002 * *$} \\
\hline & Don't work & 0 & 0.0 & 2 & 20 & 6 & 75 & & \\
\hline \multirow[t]{3}{*}{ Monthly income } & Not enugh & 12 & 54.5 & 8 & 0 & 8 & 00 & \multirow[t]{3}{*}{14.59} & \multirow[t]{3}{*}{$0.01^{*}$} \\
\hline & Enough & 8 & 36.4 & 2 & 20 & 0 & 0.0 & & \\
\hline & $\begin{array}{l}\text { More than } \\
\text { enough }\end{array}$ & 2 & 9.1 & 0 & 0.0 & 0 & 0.0 & & \\
\hline \multirow{3}{*}{$\begin{array}{l}\text { With whom he } \\
\text { live }\end{array}$} & Alone & 0 & 0.0 & 1 & 10 & 8 & 100 & \multirow[t]{3}{*}{22.29} & \multirow{3}{*}{$.0 .3 * *$} \\
\hline & With family & 22 & 100 & 7 & 70 & 0 & 0.0 & & \\
\hline & With friends & 0 & 0.0 & 2 & 20 & 0 & 0.0 & & \\
\hline
\end{tabular}




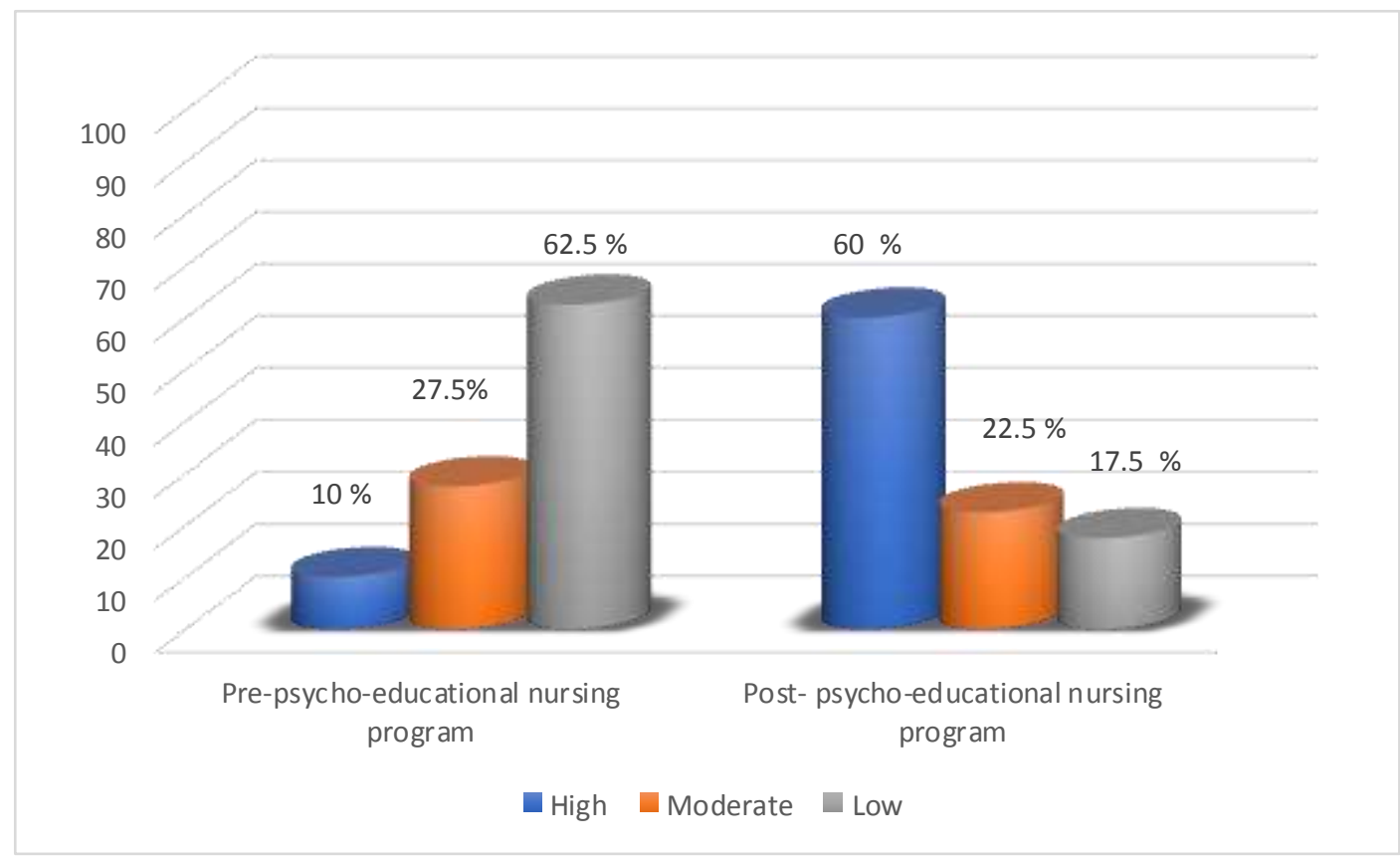

Figure (1): Level of social adjustment of the studied patients at pre and post intervention of psycho-educational nursing program $(n=40)$.

\section{Discussion}

Regarding self-esteem among studied sample pre and post program implementation, the current study results indicated that there was a highly statistical significant improvement in the mean score of all items of self-esteem post psycho educational nursing program than pre intervention program. In addition, the preset study findings reported that more than half of the studied patients had high self-esteem level post implementation of psycho-educational nursing program compared to only ten percent who had high self-esteem before implementation of the program with a statistical significant difference.

The researcher`s point of view was that before program implementation the substance abuser had low self-esteem due to stigma of substance abuse, expected others to humiliate him, thinks nobody likes him/her. Also feels loneliness and separation from others, negative perceptions towards themselves and their feeling of powerlessness. The present results agree with (Sajjadi et al., 2015) who found in his study that self-esteem, religious affiliation, socio-economic status, family environment and responsibility had lower scores.

Also, the high self-esteem after psycho educational nursing program implementation in the current study could be due to the effectiveness of the psycho educational nursing program content, activities and events on its session. This session was within the interest, and the needs of addicts that helped them to recognize their own strengths and weaknesses points., be aware of their negative thoughts, allowed substance abusers to challenge them, helped them to change negative thoughts with positive one and learned them how to overcome internal criticism (Negative self-talk).

In addition, this result can be explained that, the psycho-education program helped the patients to identified conditions or situations 
that affect self-esteem and to analyzed thoughts and beliefs about them, as being rational or irrational. Then, replace these with accurate, rational, constructive thoughts. In addition, it helped the patients to learn to accept themselves. This leads to experiencing positive emotions such as hope, positive overvaluation of his condition and finally to constructive adaptation to this state. Since Self-esteem influences the assessment of the stress situation - the better the self-esteem, the more often the patient approaches the disease as a challenge.

Psycho educational nursing program in the present study helped the addicts to treat themselves with kindness. Many of participant said that they became impressed positively by the sentence of recording (You are a value) and satisfied with themselves and realized that their life has a meaning, and hence they want to enjoy it. Another participant said that he become perceiving things with a deep and different way. This makes every moment in life worthy. Also, psycho educational nursing program encouraged individuals to talk about their experience in front of their peers who have similar experience. Motivate all members of the group and encouraged them to talk without any hesitation or fear. This supported their psychological development aspects, and enhanced their sense of self-esteem.

This result was in accordance with (AlRuwaili \& Al-Shawi, 2016) \& (Abu Attia \& El-Hassan, 2014) who mentioned that there was statistical significant improvement in the mean score of all items of self-esteem of the study group post intervention program than pre intervention program. The high level of selfesteem among addicts because of the activities and events included in the program that was applied, where behavioral training sessions, role models, and modeling to raise the self- esteem of addicts enabled them to be on the road to recovery. In addition to enabled the addict to learn and practice the skill of selfassertiveness (to say: no for drugs), from knowing the reality of the case and the possibility of treatment, and thus the possibility of returning to society naturally.

In addition, this result was in accordance with (Hamid, 2012) who mentioned that there was statistical significant improvement in the mean score of all items of self-esteem and selfconfidence of the study group post program than pre intervention program. Additionally, this result was in accordance with (Hussin et al., 2018) who mentioned that the intervention of program was succeeding in increasing selfesteem mean score compared to control group in different time interval.

Regarding social adjustment pre and post program implementation, the current study results indicated that there was a marked improvement in the mean score of all items of social adjustment as well as total social adjustment means score post intervention than pre intervention with statistical significance difference between pre and post implementation of psycho-educational nursing program.

The researcher's point of view was that before program implementation results were referred to the fact that substance abuse had been associated more broadly with impaired relationships with family and friends. The individual not only suffer from physical and psychological problems but also loses the ability to interact with family, peers and society. The labeling of person as a drug addict triggers powerful expectations of rejection from others than in turn erode confidence, disrupt social interaction and impaired social and occupational functioning. This result was in accordance with (D' Silva \& 
Aminabhavi, 2013) who found that more specially drug addicted patients had shown significantly lower adjustment in terms of home, social, emotional and educational hen compared to those patients who were not addicted to drugs

The improvement of social adjustment after program implementation illustrate the effectiveness of the psycho-educational intervention sessions and method of teaching and training skill which was within the needs and interest of the participant.

This result was in accordance with (Mohebbi etal., 2017) who found in his study an improvement in coping strategies and social adjustment after program implementation on experimental group than control group . Also This result was in accordance with (Wasila, 2018) who found that after implementation of the psycho educational program substance abusers accepted social skills and become able to appreciate the importance of positive and constructive relationships in his life, bears, social responsibility, communicates with others, and works to manage problems and conflicts.

The results of the present study denoted that the substance abusers' coping was significantly improved after implementation of the program. This may be due to the effect of the skills training of program, which included stress management techniques such as applying relaxation technicians (deep breathing - muscle relaxation exercisesmeditation) that helped substance abusers to cope with their stress, enhancing emotional and coping skills and be able to deal with anger and frustration.
In addition, the positive self-talk skills of the addict contributed to changing the addicts' perceptions about his perceived self-efficacy in dealing with previous situations, and pressures were formed. In addition, the willingness and preparation to deal with difficult situations. This method give the addict a set of skills and worked to train substance abusers to learned irrational ideas to adapt to future conditions among the most important risk factors for substance abuse.

Psycho educational nursing program included cognitive reconstruction sessions to improve mood through positive adaptive methods. i.e. modifying cognitive factors and illogical convictions, such as the conviction that drugs lead to improving mood, where it was explained that this conviction is incorrect, and the feeling of happiness because the drugs give a false sense of happiness followed by a state of decline and depression.

Participants mentioned many examples about the changed of thought process during program implementation. Client said that program helped him how to deal with negative thoughts and helped him to label his thoughts. In the beginning of the session (9) of developing skills using cognitive restructure to overcome negative thoughts, there was a participant not reacted during the 10 minutes and he mentioned that he did not want to read his thoughts. However he maintained to attend all sessions. Then after the session (12) he was able to face his thoughts and become more interested by the sessions.

As regards, relationship between patients' age and level of self-esteem post intervention of the psycho-educational nursing intervention program, the current study results demonstrated that there were statistically significant difference between level of self- 
esteem and the patients' age. The higher level of self-esteem for those who have high selfesteem are among age group between age of $35-<45$ years this could be due to this age was at a period in which individual gets maturity, could take decisions by himself, used logics and identifying reasons and able to improve their self-esteem. This result was in disagreement with (Hamid, 2012) who mentioned that there was n't statistically significant difference between patients' age and self-esteem at post intervention of psychoeducational nursing program. In addition, this result was in disagreement with (Abd Elhamid, 2018) who mentioned that there was no significant relationship between self-esteem and age.

As regards, relationship between level of education of the studied patients and their total self-esteem at post intervention of psycho- educational nursing program, the current study results demonstrated that there was highly statistically significant difference between level of self-esteem of the studied patients and their educational level; Persons with higher education were more likely to have high self-esteem. This difference could be due to educational level helped them to abstract, able to solve problem and manage the situation within the group during group discussion. This result was in accordance with (Abd Elhamid, 2018) who mentioned that there was highly significant relationship between educational level and self-esteem. In the other hand, this result was in disagreement with (Hamid, 2012) who mentioned that there was n't statistically significant difference between level of education and self-esteem at post intervention of psycho- educational nursing program.

As regards, relationship between occupation of the studied patients and their total self-esteem at post intervention of psycho- educational nursing program, the current study results demonstrated that there was highly statistically significant difference between level of self-esteem of the studied patients and their occupation. The higher level self-esteem from those who have high selfesteem are among those who were working. This could be due to feeling of productivity and independence this result was in disagreement with (Abd Elhamid, 2018) who mentioned that there was no significant relationship between self-esteem and occupation.

As regards, relationship between with whom they lived and level of self-esteem post intervention of the psycho-educational nursing intervention program; the current study results demonstrated that there was highly statistically significant difference between level of selfesteem of the studied patients and with whom they lived. the higher level of self-esteem were among those who are living with their family this could be due to family support system which helping them to accept themselves and gain self-esteem. This result was in disagreement with (Abd Elhamid, 2018) who mentioned that there was no significant relationship between self-esteem and with whom they lived.

Relationship between history of substance abuse of the studied patients and their level of self-esteem at post intervention of psychoeducational nursing program.

As regards, relationship between duration of substance abuse and level of selfesteem post intervention of the psychoeducational nursing intervention program, the current study results demonstrated that there was statistically significant difference between self-esteem and duration of substance abuse. 
From the researcher view distribution of duration of substance used may be an important determinant of population health, the present study showed significant relationship between self-esteem and duration of substance abuse; Persons with lower years of abuse were more likely to be adjusted and improved their self-esteem throughout their rehabilitation phase of treatment. This result was in disagreement with (Hamid, 2012) who mentioned that there was n't statistically significant difference between duration of substance used and self-esteem at post intervention of psycho- educational nursing program.

\section{Relationship between socio-} demographic characteristics of the studied Patients and their level of social adjustment at post intervention of psycho- educational nursing program

As regards, relationship between patients' age and their total social adjustment at post intervention of psycho- educational nursing program, the current study results demonstrated that there was statistically significant difference between level of social adjustment of the studied patients and patients' age. This result was in disagreement with (Helmy, 2016) \& (Abd Elhamid, 2018) who mentioned that there was no significant relationship between social adjustment and age.

As regards, relationship between marital status and their total social adjustment at post intervention of psycho- educational nursing program, the current study results demonstrated that there was statistically significant difference between level of social adjustment of the studied patients and marital status. This could be due to family and spouses support for their addict person where supportive spouses contributed to substance use reduction, while being divorced or widowed was associated with increased risky substance abused.

This result was in accordance with (Farag, 2019) \& (Helmy, 2016) who mentioned that there was statistical significant relationship between level of social adjustment of the studied patients and marital status. In addition, this result was in accordance with (Schnuerer et al., 2013) in his study on "Gender-specific predictors of risky alcohol use among general hospital inpatients. Gen Hosp Psychiatry". Socio-demographic-, living situation- and substance-related variables as predictors of current risky alcohol use for both female and male general hospital inpatients stated that; supportive family and spouses contributed to substance use reduction, while living alone and being divorced or widowed was associated with increased risky alcohol usage. This result was in disagreement with (Abd Elhamid, 2018) who mentioned there was no significant relationship between social adjustment and marital status.

Regarding, relationship between level of education of the studied patients and their total social adjustment at post intervention of psycho- educational nursing program, the current study results demonstrated that there was highly statistically significant difference between level of social adjustment of the studied patients and their educational level. This result was in accordance with (Farag, 2019) who mentioned that there was highly significant relationship between social adjustment and educational level. Also, this result was in accordance with (Abd-Elhalim \& Earishi, 2015) who mentioned that there was significant relationship between social adjustment and level of education. While was in disagreement with (Helmy, 2016) who 
mentioned that there was no statistical significant relationship between level of education of the studied sample and social adjustment.

As regards, relationship between occupation of the studied patients and their total social adjustment at post intervention of psycho- educational nursing program, the current study results demonstrated that there was highly statistically significant difference between level of social adjustment of the studied patients and their occupation. This result was in accordance with (Abd-Elhalim \& Earishi, 2015) who mentioned that there was significant relationship between social adjustment and occupation. This result was in disagreement with (Abd Elhamid, 2018) who mentioned that there was no statistical significant relationship between occupation of the studied sample and social adjustment.

As regards, relationship between monthly income of the studied patients and their total social adjustment at post intervention of psycho- educational nursing program, the current study results demonstrated that there was highly statistically significant difference between level of social adjustment of the studied patients and their income. This result was in accordance with (Abd Elhamid, 2018) who mentioned that there was significant relationship between social adjustment and economic status. This result was in disagreement with (Helmy, 2016) who mentioned that there was no statistical significant relationship between monthly income of the studied sample and social adjustment.

As regards, relationship between with whom they lived and their total social adjustment at post intervention of psychoeducational nursing program, the current study results demonstrated that there was statistically significant difference between level of social adjustment of the studied patients and with whom they lived. From the researcher view this could be due to family support system. This result was in accordance with $(\boldsymbol{A} \boldsymbol{b} \boldsymbol{d}$ Elhamid, 2018) who mentioned there was significant relationship between social adjustment and with whom they lived. This result was in disagreement with (Helmy, 2016) who mentioned that there was no significant relationship between social adjustment and with whom they lived.

As regards, relationship between duration, frequency of substance abuse and their total social adjustment post intervention of the psycho-educational nursing intervention program, the current study results demonstrated that there was statistically significant difference between social adjustment and both of duration of substance abuse and frequency of substance abuse. This result was in accordance with (Farag, 2019) \& (Abd Elhamid, 2018) who mentioned there was significant relationship between social adjustment and duration of substance abuse.

\section{Conclusions:}

Substance abuse influenced people's self-esteem. Low self-esteem leaded to feeling of failure, dissatisfaction of one's role in the society, dissatisfaction of quality of life, impaired interpersonal skills, social interactions and social adjustment. The psycho-educational nursing program had a positive effect on enhancement of social adjustment and self-esteem among substance abusers. There was a highly positive significant correlation between self-esteem of the studied patients and their social adjustment at post intervention of psycho-educational nursing program. 


\section{Recommendations:}

Stress management, assertiveness training and social skill training program should be given to substance abuser to relieve their psychological problems and enhance their coping patterns.

Assist the substance abuser wi identification of negative, self-defeating thoughts and with modifying them into more realistic thoughts to promote more accurate and positive thoughts about the self and others. integrated as a part of routine nursing intervention for substance abuser to enhanc their self-esteem.

A psycho educational program about social adjustment and self- esteem should be applied for substance abusers based on a treatment protocol during their hospitalization.

Applying psycho educational program at outpatient clinics and addiction treatment centers for substance abusers.

Cognitive behavioral therapy (CBT) and rational emotive therapy is recommended for all substance abuser.

Encouraging communication of feelings, recreational activity and social commitments to enhance social adjustment and self-esteem.

Mass media should increase awareness of substance abusers and their parents through educational program that educated them about causes, early detection, prevention and management of addiction.

- Further studies should be done about how to deal with psychosocial problems that leads to substance abuse.

冈 Further research on large number of substance abuser about how to cope with their problems effectively.

\section{References:-}

Abdel Wahab, E. (1990). Measuring social adjustment among inpatient schizophrenic patients in Mansoura Unpublished Egyptian Doctorate Dissertation. Faculty of Nursing, Cairo University.

Abdel Salam, Z. (2011). Effect of supportive psychotherapy on interpersonal problems, personality pathology and social adjustment among depressed women in Mansoura Unpublished Egyptian Doctorate Dissertation. Faculty of Nursing, Cairo University.

Abd-Elhalim, A. and Earishi, E., (2015). Relationship psychosocial adjustment and substance abuse. Journal of Arab and Human Sciences, 9(1). Pp. 371-429.

Abd Elhamid, M., (2018). Psychosocial Adjustment among Substance Abuser during Rehabilitation Phase of Treatment. Published master thesis in Faculty of Nursing, Ain Shams University, Egypt. Pp.98.

Abu Attia, S. and El- Hassan, L., (2014). The effectiveness of expressive therapy in reducing psychiatric disorders and improving self-esteem and social support among addicts. Journal of Educational Sciences Studies, 41(1). Pp. 139-161.

Al-Ruwaili, F. and Al-Shawi, R., (2016). The effect of a group counseling program in reducing depression and enhancing selfesteem among drug addicts in Al- Amal hospital in Saudi Arabia. Journal of Al-Quds Open University for Educational and Psychological Research and Studies, 4(13).Pp. 285-310.

American Psychiatric Association, (2016). Diagnostic and Statistical Manual of Mental Disorders, Clients with mental disorders, six edition, Text revision, P 324.

Asghari, F., Akbari., B., Shadman, R. and Saadat, S. (2016). The effect of cognitivebehavioral training on quality of life and 
aggression among drug addicted prisoners. Journal of Research \& Health, 5(4), 77 -86.

Benyamini ,Y., (2015). Health and illness perceptions. In H. S. Friedman (Ed.), The Oxford handbook of health psychology (pp. 280-293). Oxford, UK: Oxford University Press.

D 'Silva, J. and Aminabhavi, V., (2013). Adjustment, self-efficacy and psychosocial competency of drug addicted adolescents. $J$ Psychology, 4(1).Pp. 13-18.

El-Desouky, M. (2000). Self-esteem guidance. Egyptian renaissance library, 9 Adly street, Cairo.

Farag, Z., (2019). Perceived stigma, Selfstigma and social functioning among individuals with substance abuse disorders. Master thesis, Alexandria university, Faculty of nursing. Department of psychiatric nursing and mental health.

Hamid, Z., (2012). Effectiveness of group psychotherapy in improvement self-esteem and self-confidence among substance abusers in Al-Selah Medical Hospital. PHD thesis, Islamic University

Heidari, M. and Ghodusi, M., (2016). Relationship of assess self-esteem and locus of control with quality of life during treatment stages in patient referring to drug addiction rehabilitation centers. Mater Sociomed., 28(4). Pp. 263-267.

Helmy, T., (2016). Risk factors of addiction among addicted patient at Benha and Abassia mental hospitals. Published master thesis in Faculty of Nursing, Benha University, Egypt. Pp.10.

Hudson, W., (1994). Measure for clinical practice: A source book ( $2^{\text {nd }}$ ed.). New York: free press co., 35-38.

Hussin, H., Othman, M., Hussin, K. and Alias, N., (2018). The Effect of Brief
Cognitive Behavioural Therapy Group Intervention on Self Esteem among Drug Users. MATEC Web of Conferences 150.Pp. 14.

Jahedi, Z. and Reyshahri, A. (2015). The Impact of communication skills training on the adjustment of opiate addicts. International Journal of Human Resource Studies, 5(4), 128-141.

Marshall, S., Parker, P., Ciarrachi, J. and Heaven, P. (2014). Is self-esteem a cause or consequence of social support? a 4-year longitudinal study. Child Development, 85, 1275-1291.

Mohebbi, F., Moghaddasfar, T., Tajabadi, R. and Vahed, N., (2017). The Effectiveness of Life Skills Training on Psychological Symptoms and Coping Strategies in Opioid dependent patients. Nova Journal of Medical and Biological Sciences, 6(2). Online ISSN: 2292-793X.

Salam, A., Das, K., Arshad, A., Finkelstein, Y. and Bhutta, A., (2016). Interventions for Adolescent Substance Abuse: An Overview of Systematic Reviews. The Journal of Adolescent Health; 59 (4). Pp. 61-75.

Sajjadi, H., Harouni, G. and Sani, S. (2015). Personal, Familial and Environmental Determinants of Drug Abuse: A CausalComparative Study. Global Journal of Health Science; 7(4):367-374.

Schnuerer, I., Gaertner, B., Baumann, S., Rumpf, J., John, U., Hapke, U. and FreyerAdam, J., (2013). Gender-specific predictors of risky alcohol use among general hospital inpatients. Gen Hosp Psychiatry; 35(1):9-15.

Substance Abuse and Mental Health Services Administration MD (SAMHSA 2017). Substance Abuse and Mental Health Services Administration; 2018. Results from the 2017 National Survey on Drug Use and Health: Detailed tables. 
patients: a meta-analysis. BMC psychiatry journal, 16:16.

The fund for fighting and treating addiction and administration, Hotline, (2019). Incidence of substance Dependence in Egypt. Available leat: http://gate ahram. Org. e.g. / News Content / 13/54/325338/325338.

Wasila, R., (2018). The effectiveness of a group therapy program on Reduction the symptoms of relapse among substance abusers. PHD thesis, College of Humanities and Social Sciences. Department of psychology and education.

Yazdani, S. and Abardeh, H., (2018). Clinical Reasoning in Medicine: AConcept Analysis. Journal of Medical Education; 16(3). World Health Organization, (2019). Schizophrenia. Available at https: / www.who.int/mental_health/management/schi zophrenia/en/. Date of access (27/6/2019) at $(2: 30 \mathrm{am})$. 
تأثير برنامج تمريضي تعليمي نفسي علي التكيف الاجتماعي وتقدير الذات لاي مسيئ استخدام العقاقير

$$
\text { شيماء صلاح السيا, أميمة أبو بكر عثمان, معالي ابراهيم المالكي, مواهب محمود زكى }
$$

تعد إساءة إستخدام العقاقير أحد أهم الانحر افات الإجتماعية ، وهي أساس العديد من الأضرار و المشاكل

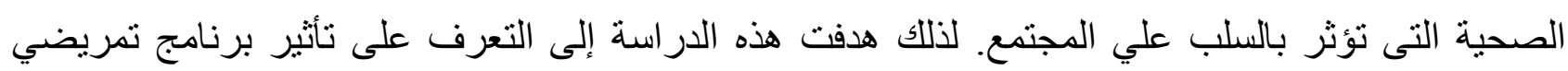

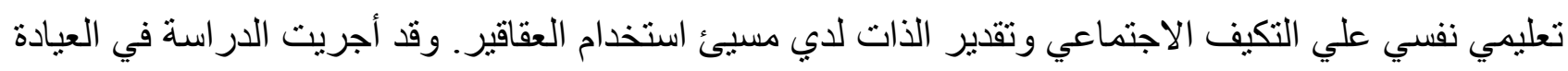
الخارجية للإدمان بمستشفى الصحة النفسية والعقلية فى مدينة بنها التابعة للأمانة العامة ـ وتم إختيار عينة

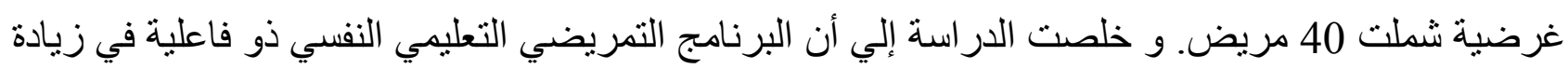

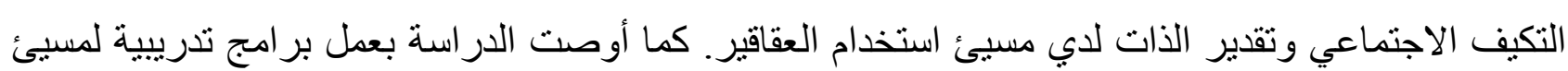

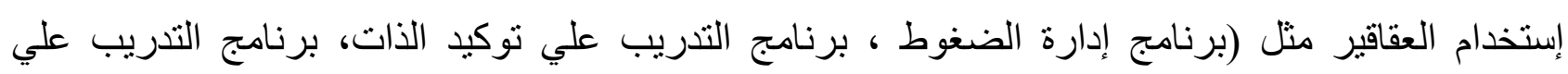
المهار ات الإجتماعية) وذللك لمساعدتهم علي التغلب علي المشاكل النفسية وتعزيز أنماط التكيف لديهم . 